We present a case of an extremely rare, atypical prostate tumour, diagnosed in a 57-year-old man, who reported pain in the pelvic area, problems with defecation and lower urinary tract symptoms (LUTS). A giant prostate tumour was diagnosed in computed tomography. The histopathological examination findings from core needle biopsy of multiple sites were not unequivocal. The patient underwent pelvic exenterative surgery. Also Bricker ileal conduit urinary diversion and sigmoidostomy were performed. Histopathological examination of the surgical specimen revealed a gastrointestinal stromal tumour originating from the prostate and infiltrating the urinary bladder and the rectum. The patient was qualified for systemic adjuvant chemotherapy, but he did not give his consent to that treatment. Clinical evaluation at 6 months following the surgery revealed major improvement in the patient's health status, but the patient still rejects adjuvant treatment.

The paper also presents an overview of the literature on gastrointestinal stromal tumour (GIST) of the prostate.

Key words: gastrointestinal stromal tumours, prostate cancer, imatinib, CD117 antigen, interstitial cells of cajal.

\section{Prostate tumour originating from interstitial cells of Cajal: a case presentation and review of the literature}

\section{Gerard Grotthuss, Slawomir Poletajew, Tomasz Dzik, Andrzej Borówka}

Department of Urology, Medical Centre of Postgraduate Education, Warsaw, Poland

\section{Introduction}

Gastrointestinal stromal tumours (GIST) are rarely occurring neoplasms originating from mesenchymal cells. As the name suggests, they usually involve the gastrointestinal tract - mainly the stomach and small bowel [1, 2]. Gastrointestinal stromal tumours (GIST) located outside the gastrointestinal tract are referred to as extra-gastrointestinal tumours (EGIST) and are extremely rare. To the best of the authors' knowledge, only 3 cases of gastrointestinal stromal tumours originating from the prostate have been reported before.

\section{Case description}

A 57-year-old man referred to the doctor with severe pain in the perineal and pelvic area, abdominal pain, as well as problems with defecation and dysuria. The pain was accompanied by dizziness and general malaise. Digital rectal examination (DRE) revealed a very large, slightly movable, spherical tumour with a smooth surface at the prostate site. Laboratory test results, including PSA concentration $(0.25 \mathrm{ng} / \mathrm{ml})$, were within reference value limits. Transabdominal ultrasound (TAUS) showed urinary bladder elevation caused by the extensive mass inside the pelvis minor. Urinary bladder walls were smooth and no dilatation was shown in the upper urinary tract. Abdominal computer tomography (CT) scan performed without contrast medium, upon the patient's request (Fig. 1), revealed the presence of an extensive, non-homogeneous tumour originating from the prostate. Multiple tumour calcifications were revealed as well. The other organs within the abdominal cavity looked normal. Pelvic lymph nodes, both visceral and retroperitoneal, were not enlarged. No bone lesions or lesions in basal lungs were revealed in the CT scan. The chest x-ray did not show any metastases.

A core finger-guided prostate biopsy of multiple sites was performed. The findings of the histopathological examination of core tissue specimens prepared using a standard technique (haematoxylin and eosin stained) were not unequivocal - the uropathologist found that the image may suggest a benign nerve sheath tumour (schwannoma), leiomyoma, fibroma or GIST.

After the biopsy, episodes of significantly severe rectal bleeding occurred, and the patient required hospitalization. On the 10th day following the biopsy, acute peritonitis was diagnosed due to acute appendicitis. Therefore an appendectomy was performed. No postoperative complications were observed, but DRE showed that the tumour, being previously homogeneous in structure and having a smooth surface, increased in size and became severely painful, heterogeneous in its inner structure and rough on the surface. The patient's health status worsened to some extent, which on one hand was explained by the peritonitis, but on the other hand by local tumour 
progression. Therefore, despite uneven histopathological diagnosis, but having in mind the increased severity of LUTS, difficulties with defecation, rectal bleeding and worsened health status, the decision was made to perform surgery with its extent to be decided upon intraoperatively. At the same time, it was assumed that the extent may involve pelvic exenterative surgery, if the tumour - from a technical point of view - could not be detached from the posterior bladder wall and anterior rectal wall, or if such detachment posed any risk of irradicality, it was assumed that the tumour was malignant.

The surgery was performed at 3 weeks following the biopsy. The peritoneal cavity was opened using a vertical incision from the epigastrium to the pubic symphysis. The prevesical space and paravesical space were shown bilaterally. The pelvis minor was filled with a very extensive tumour moving the urinary bladder forward. After partial detachment of the lateral tumour surfaces, the urinary bladder was opened in order to evaluate its interior - the vesical mucosa remained unchanged. An attempt was then made to detach the tumour from the posterior bladder wall. During the procedure, it was found out that the tumour was closely adherent to the bladder wall and, possibly, also infiltrated it. Therefore, in order to avoid the risk of irradicality, it was decided to remove the tumour with the urinary bladder. After reaching the prostate, which formed a single mass with the tumour, from the front and from both sides, it was dissected from the urethra. At this stage of the surgery it was observed that the tumour infiltrated the anterior rectal wall. Therefore, the colon was dissected at the rectosigmoid junction and - detaching along the sacral surface - the entire mass was removed involving the urinary bladder, a giant prostate with tumour lesions, seminal vesicles and rectum. The distal rectal stump was sutured, and the sigmoid stump was implanted into the opening made in the abdominal integument, situated slightly above and medially from the left anterior superior iliac spine. This was followed by the performance of Bricker ileal conduit urinary diversion. No postoperative complications were observed. The patient was discharged on the $10^{\text {th }}$ day postoperatively.

The initial report of the uropathologist reads as follows: "a tumour $8 \mathrm{~cm}$ in diameter, shows mesenchymal structure;

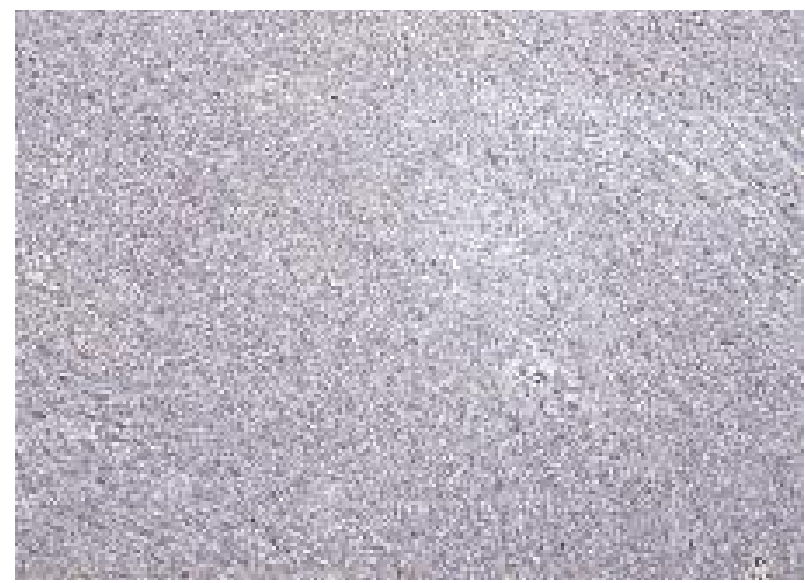

Fig. 3. Microscopic image of prostate specimen in an immunohistochemical examination. Positive reaction for CD 117. Light microscope, magnification $40 \times$ composed of fusiform cells, with extensive necrosis, it involves almost the entire prostate; a typical gland structure remained only in the prostatic apex; the tumour infiltrates the anterior rectal wall at 20-30 $\mathrm{mm}$ and is closely adherent to the bladder wall, but without infiltration; in the tumour structure 8-10 mitotic divisions per $50 \mathrm{hpf}$ are observed, with 400× magnification level; regional lymph nodes do not show

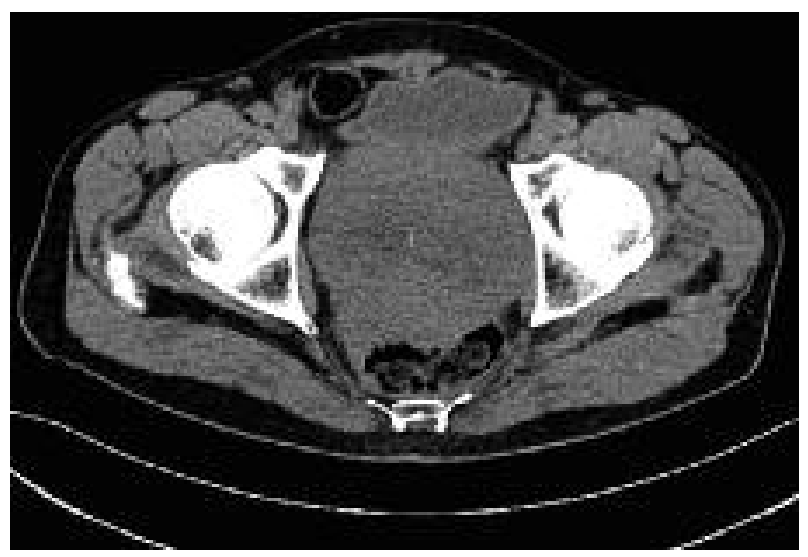

Fig. 1. Image of pelvis minor organs in abdominal CT scan an extensive mass visible at the prostate site

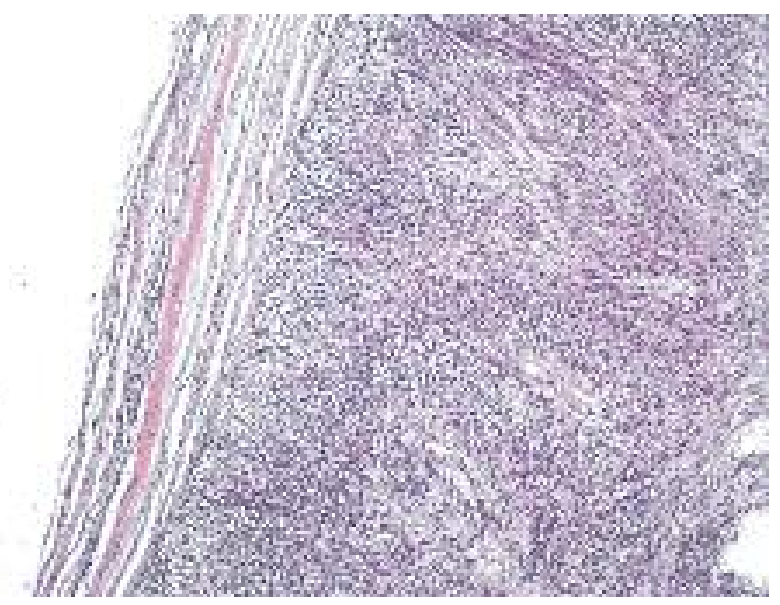

Fig. 2. Microscopic image of prostate specimen. Mesenchymal structure and extensive necrosis are visible. Light microscope, magnification $40 x$

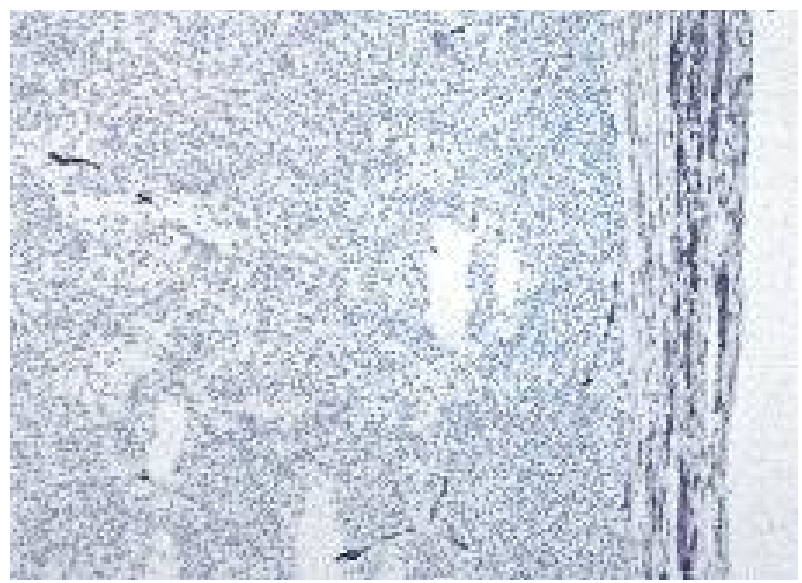

Fig. 4. Microscopic image of prostate specimen in an immunohistochemical examination. Negative reaction for SMA (smooth muscle actin). Light microscope, magnification $40 \times$ 
neoplastic lesions" (Fig. 2). Due to strong GIST suspicion, immunohistochemical examination was performed, which revealed positive reaction for CD 117 in all tumour cells (Fig. 3), positive reaction for S-100 in some tumour cells, and no reaction for smooth muscle actin (SMA) (Fig. 4). Finally, EGIST was diagnosed originating from the prostate.

The patient was referred to the oncologist and qualified for systemic adjuvant therapy with imatinib, but until now the patient has not given his consent to the therapy. Clinical evaluation at 6 months following the surgery revealed an improvement in the patient's health status and pain resolution. TAUS revealed a normal image of the upper urinary tract and kidneys. A CT scan of the abdomen and pelvis was recommended, but the patient did not give his consent to that procedure.

\section{Discussion}

Gastrointestinal stromal tumours (GIST) originate from the muscular layer of the gastrointestinal mucous membrane $[3,4]$. The first description of interstitial cells, being the stromal element of this layer, comes from 1889 and its author is Santiago Ramon y Cajal, a Spanish neuroanatomist [5]. In his honour, the cells are referred to as Cajal cells. The study of Cajal cells proved that they serve as specific pacemakers creating a basal electrical rhythm and causing contraction of smooth muscles as a consequence (peristalsis) [1].

Originally it was thought that the only GIST location could be the gastrointestinal tract. Smet proved that Cajal cells may also be present in the urinary bladder wall, thus proving that GIST may also originate from this organ (EGIST) [6]. The prostate is a particularly specific EGIST location [7-10]. Cases of other EGIST locations have also been reported, namely the greater omentum, mesentery, uterus, ovary, scrotum, and retroperitoneal space [11-15].

GIST occurrence and development is a result of mutation of proto-oncogenes, such as c-kit or PDGFRA (plateletderived growth factor receptor, alpha polypeptide), coding tyrosine kinase (KIT) [16, 17]. Phosphorylated KIT stimulates intercellular transmission, affecting proliferation, adhesion, apoptosis, cell survival rate and cellular differentiation [1]. KIT-coding protein mutations may result in many different conditions, e.g. chronic myeloproliferative syndrome, mastocytosis and stromal tumours.

In the past, GIST were often misdiagnosed as leiomyoma, leiomyosarcoma, neurinoma or schwannoma. It was the introduction of immunohistochemical examination which enabled significant differences in the immunophenotypes of the tumours to be indicated [1].

GIST are mesenchymal tumours, usually composed of homogeneous, densely located fusiform cells with a slight nuclear atypia. Approximately $95 \%$ of GIST cells show CD 117 expression (cluster of differentiation 117), a highly sensitive and specific immunochemical KIT receptor indicator $[18,19]$. Other immunohistochemical GIST indicators are CD34 (cluster of differentiation 34), SMA (smooth muscle actin), S-100 (a family of calcium-binding proteins) and desmin (intermediate filament of muscle cells).

GIST malignancy potential varies a lot. The malignancy risk assessment is based on the tumour size and/or cellular mitotic index (CMI). The highest risk is related to tumours with the size exceeding $5 \mathrm{~cm}$ and the presence of more than 5 mitotic divisions per $50 \mathrm{hpf}$, at 400x magnification, and tumours with the size exceeding $10 \mathrm{~cm}$ and the presence of more than 10 mitotic divisions per $50 \mathrm{hpf}$ [20]. In the case of GIST with a large malignancy potential, such findings as liver metastases or symptoms of infiltration to neighbouring structures are quite frequent.

The basic method for imaging in GIST is a CT scan using contrast medium. The popularity of this examination results from its availability and usefulness, as well as the possibility for imaging of organs inaccessible in endoscopic examinations [1]. Based on the CT scan it is possible to determine the macroscopic tumour structure, its size and stage of progression (both local and locoregional) as well as lymph node enlargement and the existence of distant metastases. The examination also enables biopsy performance [21]. The basic disadvantage of CT scans in pelvic GIST diagnostics is difficulty in differential diagnosis with myomas [22].

Table 1. Summary of diagnostics and treatment in patients with EGIST of the prostate

\begin{tabular}{|c|c|c|c|c|c|c|c|}
\hline Author & $\begin{array}{c}\text { Publication } \\
\text { year }\end{array}$ & $\begin{array}{c}\text { Patient's } \\
\text { age (years) }\end{array}$ & $\begin{array}{c}\text { Main } \\
\text { symptoms }\end{array}$ & Surgery & Chtx & $\begin{array}{l}\text { Follow- } \\
\text { up time }\end{array}$ & $\begin{array}{l}\text { Follow-up } \\
\text { results }\end{array}$ \\
\hline $\begin{array}{l}\text { Van der } \\
\text { Aa et al. [10] }\end{array}$ & 2005 & 49 & AUR & - & Imatinib & 24 months & $\begin{array}{l}\text { patient in good condition, } \\
\text { reduction of tumour mass } \\
\text { and metastases }\end{array}$ \\
\hline $\begin{array}{l}\text { Lee et al. } \\
\text { [12] }\end{array}$ & 2006 & 75 & $\begin{array}{l}\text { LUTS, } \\
\text { episodes } \\
\text { of AUR }\end{array}$ & $\begin{array}{l}\text { TURP } \rightarrow \text { dia- } \\
\text { gnosis of } \\
\text { EGIST } \rightarrow \text { LRP }\end{array}$ & - & 6 months & $\begin{array}{l}\text { patient in good condi- } \\
\text { tion, no signs of progression } \\
\text { of the disease, mild urinary } \\
\text { incontinence }\end{array}$ \\
\hline $\begin{array}{l}\text { Yinghao } \\
\text { et al. [11] }\end{array}$ & 2007 & 49 & $\begin{array}{l}\text { perineal } \\
\text { pain }\end{array}$ & $\mathrm{RP}$ & - & 14 months & $\begin{array}{l}\text { patient in good condition, no } \\
\text { signs of progression of the } \\
\text { disease }\end{array}$ \\
\hline our case & 2011 & 57 & $\begin{array}{l}\text { pelvic and perineal } \\
\text { pain, LUTS, } \\
\text { problems with } \\
\text { defecation }\end{array}$ & $\begin{array}{l}\text { Bx } \rightarrow \text { dia- } \\
\text { gnosis of } \\
\text { EGIST } \rightarrow \text { pelvic } \\
\text { exenteration }\end{array}$ & - & 5 months & $\begin{array}{l}\text { patient in good condition, } \\
\text { refused adjuvant chemotherapy, } \\
\text { lack of postoperative CT }\end{array}$ \\
\hline
\end{tabular}

Chtx - chemotherapy; AUR - acute urinary retention; LUTS - lower urinary tract symptoms; TURP - transurethral resection of the prostate; $L R P$ - laparoscopic radical prostatectomy; $R P$ - radical prostatectomy; $B x$ - ultrasound guided transrectal biopsy of the prostate 
Differential GIST diagnosis with other mesenchymal tumours (leiomyoma, leiomyosarcoma) is possible only based on intestinal endoscopic ultrasound, as GIST are more echogenic and produce a more intense ultrasound signal [23]. It is possible to perform a thin-needle tumour biopsy with endoultrasound guidance [24].

In the case of GIST, positron emission tomography (PET) using fluorodeoxyglucose (FDG) is a less sensitive method compared to CT scan. Nevertheless, it is an important source of information about the tumour's biological activity - it helps to distinguish the tissues with increased metabolism from metabolically inactive necrotic tissues [25].

Standard treatment involves radical tumour removal. A regional lymphadenectomy is not usually essential, as GIST metastases to lymph nodes occur very rarely [26]. Significant progress in GIST treatment has been made since the introduction of the tyrosine kinase inhibitors imatinib (Glivec) and sunitinib (Sutent); the latter is applied if the tumour shows resistance to the former [1]. Chemotherapy is recommended in the case of (i) extensive GIST, which cannot be subject to radical surgery - KIT inhibitor administration may help decrease the tumour mass and allow for the resection (neoadjuvant therapy); (ii) irradical GIST resection or after radical resection of large sized or high potential tumours (adjuvant therapy); (iii) generalized carcinoma (palliative treatment). Imatinib is administered in the dose of $400 \mathrm{mg} /$ day. Sunitinib is usually administered for the period of 4 weeks in a dose of $50 \mathrm{mg} /$ day, followed by a 2-week interval. One course lasts for 6 weeks.

Only 3 cases of patients with prostate EGIST have been reported previously [8-10] - the present case study describes another patient with the same carcinoma. The first EGIST case was reported in 2005 [8]. The tumour was diagnosed in a 49-year-old patient with acute urinary retention due to severe prostate enlargement. The tumour nature was assessed based on histopathological examination of the specimen collected at prostate biopsy. Numerous metastases were found in the patient's liver. Treatment with imatinib was started. The case report involves a 100-week follow-up period. At the end of the follow-up period the patient's health status was referred to as good. Significant tumour size reduction was observed in the prostate and in the liver metastases.

The review of the literature concerning the patients diagnosed and treated due to prostate EGIST may be summarized as follows:

- the youngest patient diagnosed with EGIST was 49 years old, the oldest one was 75 years old, the mean age was 57.7 years;

- the leading EGIST symptom was LUTS, in particular dys uria - in one patient LUTS led to several episodes of severe urinary retention; in all the patients DRE revealed severe prostate enlargement;

- laboratory test results, in particular prostate specific antigen (PSA) serum levels, were within the normal range (ranging from $0.02 \mathrm{ng} / \mathrm{ml}$ to $1.36 \mathrm{ng} / \mathrm{ml}$ ) and did not suggest prostate cancer. They were also inadequate to the degree of prostate enlargement, if the diagnosis was a benign prostate hyperplasia;

- most prostate EGIST were significantly large (from $67 \times$ $\times 56 \times 55 \mathrm{~mm}$ to $142 \times 96 \times 140 \mathrm{~mm}$ ); in one patient infil- tration of seminal vesicles was observed; in one patient at diagnosis, generalized carcinoma was revealed in the form of numerous liver metastases;

- in one patient the diagnosis of prostate EGIST was based on the histopathological examination of the tissue specimen obtained via transrectal core biopsy; in one patient the tumour nature was assessed after histopathological examination of tissue fragments after transurethral electro-resection of the prostate (TURP) performed due to initially diagnosed benign prostatic hyperplasia (BPH);

- surgical treatment was implemented in two patients: radical prostatectomy was performed without adjuvant chemotherapy; the postoperative follow-up period was 6 and 14 months respectively; in both patients neither local tumour recurrence nor distant metastases were reported during the follow-up period;

- palliative systemic treatment with imatinib was implemented in one patient, due to numerous liver metastases.

A summary of the diagnostic and therapeutic course in patients with prostate EGIST is shown in table 1.

Apart from the three quoted cases of EGIST originating from the prostate, the literature described the cases of a total of 15 patients with rectal GIST infiltrating the prostate [22, 27-31]. Predominant symptoms in those patients were LUTS and the sensation of a filled rectum, and the most significant abnormality revealed in physical examination was an extensive pelvic tumour. In the majority of the described patients, initially prostate cancer was diagnosed, and rectal GIST was finally diagnosed after histopathological examination of the specimen collected intraoperatively.

Special interest to differentiate if our patient had EGIST of the prostate infiltrating the rectum or GIST of the rectum infiltrating the prostate should be taken. Clinically, at the time of imaging, we found the prostate tumour, while the rectal wall was assessed to be smooth, with no pathology. Simultaneously, symptoms were more suggestive of pathology of the prostate than the rectum. The patient complained of perineal and abdominal pain, and lower urinary tract symptoms, not reporting bowel habit change or bloody stool passage. Finally, our pathologist diagnosed EGIST of the prostate, excluding GIST of the rectum based on the patient's history (no rectal pathology 3 months before operation and infiltration of the rectum after the surgery), macroscopic image (tumour mass located in the prostate), and microscopic image (fusiform cells involving almost entire prostate; discrete infiltration of the anterior rectal wall).

The patient described in the present paper and the characteristics of prostate EGIST in this patient are similar to the cases of most patients reported in the literature. The tumour occurred in a relatively young patient and at first it gave only slight symptoms. The symptoms occurred when the tumour was already significantly large in size. The leading symptoms were dysuria and difficulties with defecation, especially severe pain in the perineal area. After the initial physical examination, we suspected that the extensive tumour palpable in DRE was neither BPH nor prostate cancer. Therefore a transrectal core prostate biopsy was performed without delay in this patient. Its findings were not unequivocal, but the uropathologist suggested GIST as a possible diag- 
nosis. Taking into account the visible change in the tumour characteristics, which occurred after the biopsy and exacerbation of symptoms reported by the patient, we ceased histopathological examination of the tumour and simply assumed that it might be malignant. Therefore the decision was made concerning radical surgery, and preoperatively we only assumed the possibility of radical prostatectomy, while not rejecting the possibility of cystoprostatectomy. The final decision concerning such extensive surgery was made intraoperatively, after concluding that the tumour could not be safely detached from both the anterior rectal wall and the posterior bladder wall. As the histopathological examination proved that the surgical margins were negative and confirmed that there were no metastases to the regional lymph nodes, we were not certain whether the patient needed systemic adjuvant therapy with imatinib. We referred the patient to the oncologist, in order to have this question answered. After an oncological consultation it was decided that adjuvant therapy with imatinib was necessary, but the patient rejected it. Based on the observation during the follow-up period lasting for 6 months postoperatively so far, it is hard to state whether the patient's decision to reject the therapy with imatinib was reasonable.

\section{References}

1. Steigen SE, Eide TJ. Gastrointestinal stromal tumors (GISTS): a review. APMIS 2009; 117: 73-86.

2. Bucher P, Egger JF, Buhler LH, Morel P. Management of gastrointestinal stromal tumours: from diagnosis to treatment. Swiss Med Wkly 2004; 134: 145-53.

3. Herrera GA, Pinto de MH, Grizzle WE, Han SG. Malignant small bowel neoplasm of enteric plexus derivation (plexosarcoma). Light and electron microscopic study confirming the origin of the neoplasm. Dig Dis Sci 1984; 29: 275-84.

4. Lee JR, Joshi V, Griffin JW Jr, Lasota J, Miettinen M. Gastrointestinal autonomic nerve tumor: immunohistochemical and molecular identity with gastrointestinal stromal tumor. Am J Surg Pathol 2001; 25: 979-87.

5. Thuneberg L. One hundred years of interstitial cells of Cajal. Microsc Res Tech 1999; 47: 223-38.

6. Smet PJ, Jonavicius J, Marshall VR, de Vente J. Distribution of nitric oxide synthase-immunoreactive nerves and identification of the cellular targets of nitric oxide in guinea-pig and human urinary bladder by cGMP immunohistochemistry. Neuroscience 1996; 71: 337-48.

7. Van der Aa F, Roskams T, Blyweert W, De Ridder D. Interstitial cells in the human prostate: a new therapeutic target? Prostate 2003 56: 250-5.

8. Van der Aa F, Sciot R, Blyweert W, Ost D, Van Poppel H, Van Oosterom A, Debiec-Rychter M, De Ridder D. Gastrointestinal stromal tumor of the prostate. Urology 2005; 65: 388.

9. Yinghao S, Bo Y, Xiaofeng G. Extragastrointestinal stromal tumor possibly originating from the prostate. Int J Urol 2007; 14: 869-71

10. Lee $\mathrm{CH}$, Lin YH, Lin HY, Lee CM, Chu JS. Gastrointestinal stromal tumor of the prostate: a case report and literature review. Hum Pathol 2006; 37: 1361-5.

11. Reith JD, Goldblum JR, Lyles RH, Weiss SW. Extragastrointestinal (Soft Tissue) stromal tumors: an analysis of 48 cases with emphasis on histologic predictors of outcome. Mod Pathol 2000; 13: 577-85.

12. Peitsidis P, Zarganis P, Trichia H, Vorgias G, Smith JR, Akrivos T. Extragastrointestinal stromal tumor mimicking a uterine tumor. A rare clinical entity. Int J Gynecol Cancer 2008; 18: 1115-8.

13. Kang SH, Kim MJ, Park MG, et al. Extragastrointestinal stromal tumor presenting as a scrotal mass: an unusual case. Asian J Androl 2007; 9: 275-9.
14. Ferchichi L, Kourda N, Zermani R, Aouem J, Zaouche A, Abdjellil Z, Najah N, Baltagi Ben Jilani S. Extragastrointestinal stromal tumors: a report of 4 cases. Ann Chir 2006; 131: 271-5.

15. Gao YN, Jiang GQ, Liu JX, Tang WS, Chen LZ. Preoperational mis diagnosis of extragastrointestinal stromal tumors as ovarian cancer: report of three cases with literature review. Zhonghua Fu Chan Ke Za Zhi 2005; 40: 339-41.

16. Hirota S, Isozaki K, Moriyama Y, et al. Gain-of-function mutations of c-kit in human gastrointestinal stromal tumors. Science 1998; 279: 577-80.

17. Heinrich MC, Corless CL, Duensing A, et al. PDGFRA activating mutations in gastrointestinal stromal tumors. Science 2003; 299: 708-10.

18. Miettinen M, Lasota J. Gastrointestinal stromal tumors - definition, clinical, histological, immunohistochemical, and molecular genetic features and differential diagnosis. Virchows Arch 2001; 438: 1-12.

19. Miettinen M, Lasota J, Sobin LH. Gastrointestinal stromal tumors of the stomach in children and young adults: a clinicopathologic, immunohistochemical, and molecular genetic study of 44 cases with long-term follow-up and review of the literature. Am J Surg Pathol 2005; 29: 1373-81.

20. Fletcher CD, Berman JJ, Corless C, et al. Diagnosis of gastrointestinal stromal tumors: A consensus approach. Hum Pathol 2002; 33: 459-65.

21. Lau S, Tam KF, Kam CK, Lui CY, Siu CW, Lam HS, Mak KL. Imaging of gastrointestinal stromal tumour (GIST). Clin Radiol 2004; 59: 487-98.

22. Loeb S, Lotan TL, Thornton K, Gearhart SL, Schoenberg MP. A case of gastrointestinal stromal tumor diagnosed on prostate biopsy. Nat Clin Pract Urol 2009; 6: 54-7.

23. Okai T, Minamoto T, Ohtsubo K, Minato H, Kurumaya H, Oda Y, Mai M, Sawabu N. Endosonographic evaluation of c-kit-positive gastrointestinal stromal tumor. Abdom Imag 2003; 28: 301-7.

24. Stelow EB, Stanley MW, Mallery S, Lai R, Linzie BM, Bardales RH. Endoscopic ultrasound-guided fine-needle aspiration findings of gastrointestinal leiomyomas and gastrointestinal stromal tumors. Am J Clin Pathol 2003; 119: 703-8.

25. Goerres GW, Stupp R, Barghouth G, Hany TF, Pestalozzi B, Dizendorf E, Schnyder P, Luthi F, von Schulthess GK, Leyvraz S. The value of PET, CT and in-line PET/CT in patients with gastrointestinal stromal tumours: long-term outcome of treatment with imatinib mesylate. Eur J Nucl Med Mol Imag 2005; 32: 153-62.

26. Everett $M$, Gutman $H$. Surgical management of gastrointestinal stromal tumors: Analysis of outcome with respect to surgical margins and technique. J Surg Oncol 2009; 99: 318.

27. Arce-Lara C, Shah MH, Jimenez RE. Gastrointestinal stromal tumors involving the prostate: presentation, course, and therapeutic approach. Urology 2007; 69: 1209.

28. Herawi M, Montgomery EA, Epstein JI. Gastrointestinal stromal tumors (GISTs) on prostate needle biopsy: A clinicopathologic study of 8 cases. Am J Surg Pathol 2006; 30: 1389-95.

29. de la Roza G, Naqvi A, Clark K. Gastrointestinal stromal tumors presenting as a prostatic mass. Can J Urol 2009; 16: 4502-6.

30. Dickson BC, Srigley JR, Pollett AF, Blackstein ME, Honey JD, Juco JW. Rectal gastrointestinal stromal tumor mimicking a primary prostatic lesion. Can J Urol 2008; 15: 4112-4.

31. Kuruma H, Ao T, Suyama K, Okuno N, Mizoguchi H, Murayama M, Koshiba K, Motoori T. A case of gastrointestinal stromal tumor of rectum, difficult to differentiate from leiomyosarcoma of prostate. Nippon Hinyokika Gakkai Zasshi 2001; 92: 624-7.

\section{Address for correspondence}

\section{Slawomir Poletajew MD}

Department of Urology

Medical Centre of Postgraduate Education

Bursztynowa 2

04-749 Warsaw

e-mail: slawomir.poletajew@gmail.com 